\title{
Business Ethics and Systems Thinking
}

\author{
Anders Nilsson ${ }^{1}$ and Mats Westerberg ${ }^{1}$
}

Received April 20, 1997

This paper discusses the development of research in business ethics and recent directions taken by scholars in the field. We also analyze ethical considerations in systems theory and speculate on the possibilities of examining business ethics from a systemic perspective.

KEY WORDS: business ethics; systems thinking.

\section{INTRODUCTION}

Business and ethics have for ages been leading separate lives. Real-life management behavior and the ethical considerations of philosophers and theologians have been worlds apart. Carr's (1994) famous poker analogy is a good example of how the relation between management and ethics was regarded by most business people until not long ago:

The ethics of business are not those of society, but rather those of the poker game. (p. 28)

According to Carr, bluffing is acceptable as long as the opponents know that you might do it, i.e., as long as all players are aware of the rules of the game. The rules of the business game are set by the law. Anything that is legal is also ethical. Ethical dilemmas in business have been left to each decision-maker's private conscience. And "businessmen that can't stand the heat, should stay out of the kitchen" (Carr, 1994, p. 30). In other words, people who want to be ethical in another sense than just following the law have no place in business, at least not in managerial positions. However, it may be argued that the laws of today are the ethics of yesterday. In order to be in touch with today's ethics, people and companies must listen to what the demands are today (Dillon, 1991).

\footnotetext{
'Luleå University of Technology, Department of Business Administration and Social Sciences, Division of Management Control, S-971 87 Luleå, Sweden.
} 
Furthermore, there are indications that business often has had goals or traditions counter to those of ethics. Generally speaking, business can be related to self-interest, and ethics to doing good for others. Business is usually a game for the powerful, whereas ethics rather has its concerns for the weak. Lastly, business is a modern and applied discipline, compared to the ancient and (mostly) theoretical discipline of ethics (Singer, 1994).

The last years have, however, shown some changes that portend a future where ethics and business not only can, but indeed must, go together. In the long run, doing business without concern for ethics will be the surest way to fail (Dillon, 1991). This is partly due to scandals in business, government and elsewhere, which have led to an increasing attention being devoted to ethical values from the public, business enterprises, and the research community. In short, the ethical values of managers are on everybody's lips (e.g., Harris, 1990).

Even though concepts such as fairness and justice can be traced to Plato and Aristotle in the fifth century BC (Gatewood and Caroll, 1991), there is a risk that the recent awakening of ethical concerns in management will turn into just another "management fad." When companies turn to ethics only for reasons of increasing profits, there is no real commitment to ethical behavior. When choosing between doing the right thing and making an extra dollar, these firms still will be ambiguous (Hoffman, 1994). Moreover, ethical codes in firms will have little influence on ethical behavior of employees if management does not follow the codes (Stead et al., 1990; cf. also Hambrick and Mason, 1986; Miller and Toulouse, 1986). Sometimes, management is reluctant to enforce ethical standards since they believe it might cause problems in the short run. This is referred to as "moral muteness" and implies forsaking long-term considerations for short-term benefits (Bird and Waters, 1989). Another indication that change will not be easily attained is the fact that marketing managers' ethical behavior is virtually the same today as in the early eighties (Premeaux and Mondy, 1993).

The potential conflict between traditional business values and ethics, often related to managerial short-sightedness, indicates a need for a more holistic, long-term perspective. Systems thinking is a discipline that claims to have such characteristics. Can systems thinking reduce the apparent gap between business and ethics?

In this paper we briefly review part of the business ethics debate during the last years. Then we look at how business ethics can be defined. We also discuss why systems theory could be a good starting point when studying business ethics. Following this, we review and analyze four methodologies based on systems theory from an ethical standpoint. Finally, the paper closes with some concluding remarks. 


\section{WHY BUSINESS ETHICS TODAY?}

\subsection{Managed Greed Becomes Unmanaged Greed}

After World War II, working life in the Western Hemisphere has been distinguished by four important characteristics (Nash, 1994):

- sustained economic growth,

- an expectation of lifetime employment,

- a homogeneous workforce, and

- a national educational system that stresses literacy, mathematical ability, and basic Judeo-Christian values.

These fundamentals made possible a business philosophy of "managed greed," a pursuit of self interest within the bounds of law and custom. Such a utilitarian management model implies that everybody plays the game according to its rule as long as there is something in it (i.e., monetary rewards) for everyone.

These factors, previously sufficient to stimulate productivity and teamwork, allowed for "managed greed." Today all the above conditions are, if not invalid, at least seriously questioned. Economic recession and heavy competition decrease the likelihood of immediate cash rewards, thereby putting further pressure on managers in terms of corporate performance (Dolenga, 1990). The ideals of lifetime employment have been crushed by increasing workforce mobility and numerous mergers and downsizings. The workforce of today is heterogeneous, with different nationalities, races, and sexes, and schools have dropped ethics from their curriculums. Thus, both employees and management are placed in a situation where they risk compromising their personal values for "the good of the company" (Carroll, 1994). In short, the ethos of managed greed has become unmanageable (Nash, 1994).

One approach to overcoming these problems may be to turn to ethics. However, businesses often have maintained the same basic management approach, only with a stronger emphasis on control mechanisms to detect actions out of line. Says one manager:

Motivate for greed and set up a strong system of controls to ensure that if someone steps over the boundaries, they'll get caught and be penalized. (Nash, 1994, p. 18)

\subsection{A Step on the Way}

In Japan the above scenario has not occurred to the same extent. Instead, group ethics is often given priority over short term profits. Cooperation instead of competition, trust instead of distrust and a win-win situation instead of a zero-sum game (Gundling, 1991). There are also in our society many islands 
where group ethics reign in business settings (e.g., small firms or departments in larger organizations). In fact our civilization is built more on cooperation than on exploitation [see Axelrod (1984; cited by Hanson, 1991) for an elaboration on this]. However, these groups limit their ethical concerns to their internal stakeholders. This could mean that customers, suppliers, competitors, the environment, and other external stakeholders are excluded from ethical considerations. In order to carry out a successful ethical dialogue, such external forces must also be included. If ethical conduct concerns only the people who carry out the work, the Mafia could be considered ethical since decisions often are based on an internal agreement (consensus). Their deeds are not ethical, however, since outsiders suffer from their decisions such as future drug addicts, loan shark victims, etc. (Pruzan and Thyssen, 1990). To be successful in the long run, a company must be in dialogue with society at large on every topic of mutual concern to the two entities (Pastin, 1994; see also Kahn, 1990).

Even though Japanese management expresses ethical concerns more clearly than most Western corporations, there is a risk in "importing" their values without considering the consequences. If adopted uncritically, they may turn into "management gizmos" (Pastin, 1994).

For an ethical firm, the question, "Does it pay to do the right thing?" is irrelevant. Such a question would imply that ethics is secondary to profits (Dillon, 1991). A "'lots of money-lots of 'ethics,' and vice versa, rule." Ethical considerations should always come first. In the next part, we try to identify some desirable characteristics of an ethical decision and an ethical decisionmaker.

\subsection{Ethical Decision-Making}

Basing his analysis on game theory, Hanson (1991) concludes that in the long run, we can gain from cooperation, although the rational choice for a game theorist is likely to be deception. The rational-choice approach may fall prey to the very same short-sightedness that often leads to unethical behavior in business. Three prerequisites for ethical behavior are identified.

(1) The notion of a larger game. This means that we cannot compare our performance with just one opponent, but must compare it with the business community at large-even those with whom we do not deal directly.

(2) The notion of an ongoing game, i.e., emphasizing long-term performance as opposed to short-term gains.

(3) The notion of effective retaliation. Deceptions shall not pass without punishment.

This new set of conditions would lead to cooperation being the best strategy. However, these conditions seldom are at work in the business community. Often large firms are treated according to different standards than small firms, thus 
violating condition 1. Many markets have, at least in their early stages, few rules and many opportunities for making large profits on ethically questionable businesses that are likely to be regulated by time. This puts an emphasis on making fast profits, clearly violating condition 2 . Lastly, there are not always penalties imposed for those who are deceptive, either because the law is too soft or the punishment is too lenient (Hanson, 1991).

One could argue that the entire discussion above is not really about ethics but, rather, about rules or codes. The time lag in legislation impedes the efficiency of nules set by law. But even so, Hyman et al. (1990) contest that ethical codes never can be enough. What if managers instead follow their inner convictions, that are based on ethical foundations? It is clear that managers do not always act according to Weber's (1947) formal rationality. Kitching et al. (1994) found that "irrational" or noneconomic factors influence small firms' decision making. Factors such as fairness to customers and employees, as well as perceptions of the value of the services provided were all considered important. Would such an approach result in ethical decisions? Not necessarily, as can be seen from the following case:

\footnotetext{
The owner of an American paper mill went to an environmental conference and stepped out as a reformed citizen. He pledged that from that day on he would do everything in order to reduce pollution from his mill. Accordingly, he invested millions of dollars on pollution reducing equipment. The sad part of the story is that he also drove his company into bankruptcy at the same time, since his competitors spent a lot less on environmental issues. In the end, not only did 400 people loose their jobs, but the river remained polluted. (Lodge, 1977; cited by Hoffman, 1994).
}

The above "case" illustrates that focusing entirely on one stakeholder seems to be the wrong approach. Instead, some suggest that in order to make ethical decisions, managers must ask themselves a number of questions concerning all the stakeholders of the company. For example, "How would my decision affect customer relations if someone got to know?" This way managers would find out when more work is needed on a decision for it to be an ethical one (Hyman et al., 1990). Confer the notion of an "ideal speech situation" (Habermas, 1984; cited by Klein and Hirschheim, 1991).

What, then, is required for ethical managerial behavior? Drawing on the artificial intelligence idea of a "moral judge" or an "ideal observer," Firth (1952; cited by Khalil, 1993) identifies the following attributes of a moral decision-maker:

- knowledge of all relevant facts,

- in-biasedness,

- freedom from disturbing passion, and

- the ability to vividly imagine the feelings and circumstances of the parties involved.

While the above characteristics could be regarded as an ideal vision, it is also an unrealistic description of the ethical decision-maker, based on the rational- 
actor metaphor. Khalil (1993) argues against putting an expert system in charge of ethical decisions. Ethics is so complex and situation specific that it cannot be encompassed in a program. Since two identical situations only rarely can be found, it takes cognitive power from the decision-maker in order to, through reasoning, come up with a new ethical decision.

A more useful view of ethical management behavior can be found in the works of Maclagan and Snell (1992). In their view, if decisions are to be ethical, they must be made by the managers themselves. Three corresponding attributes are identified:

- Cognitive skills. Both in terms of understanding organizational behavior and having an ability to engage in ethical reasoning.

- Personal and interpersonal skills and qualities, such as integrity, an ability to listen to and respect others' viewpoints, etc.

- Self-knowledge, especially knowing one's personal values and being able to reconcile these with what happens at the workplace.

The above qualities of "cognitive skills" and "self-knowledge" can be related to Brehmer's (1992) work on dynamic decision-making, especially the notion of "heuristic competence." Failures will follow, for example, if responsibility is delegated inadequately or scapegoats are pointed out. Therefore, it is obvious that both Maclagan and Snell and Brehmer stress the importance of personal and interpersonal skills.

Researchers debate whether ethical competence is a question of having the right values (de Raadt, 1995) or having an ability to resolve ethical dilemmas according to one's own values irrespective of what these values stand for (Maclagan, 1992). Pastin (1994), for example, contends that an entity is warrented in holding an ethical belief to the extent that it can be tested and rejected (cf. Popper's critical rationalism). According to Pastin, a view where basic assumptions cannot be tested or rejected would be superstitious. Many managers commit themselves to a certain belief to such an extent that this belief cannot be challenged ["sunk ego" (Pastin, 1994)].

According to another perspective, what makes us ethical or moral beings is our free will (LeChat, 1986; cited by Khalil, 1993). A decision taken in accordance with an ethical rule is not ethical or moral by default, but only if made by free will. This could be the reason why so many researchers and practitioners point out that ethical codes are not enough (e.g., Hyman et al., 1990; Hoffman, 1994).

Is ethics merely a matter of opinions or are there some fundamental ground rules to the field? In order to be able to proceed, an examination of ethics definitions is required. 


\section{THE CONCEPT OF (BUSINESS) ETHICS}

Ethics as a research area can be defined as

... the inquiry into the nature and grounds of morality where the term morality is taken to mean moral judgments, standards and rules of conduct. (Taylor, 1975; cited by Khalil, 1993, p. 314)

Carmichael and Drummond (1989) suggest that the person's ethics are the ground rules for action, and that these rules define which actions are personally permissible. An ethical issue is at hand when a person's freely performed actions have consequences for others (Velasquez and Rostankowski, 1985; cited by Jones, 1991, p. 367).

Business ethics is not a field with its own separate standards. Rather, it is about how individuals are faced with ethical problems in a business setting (Nash, 1994; Pruzan and Thyssen, 1990). This, more recent, view of business ethics is contrary to the poker analogy of Carr (1968). It appears to the present authors that this orientation is representative for most researchers and that it is becoming increasingly popular amongst business people.

Based on the above, it is our impression that a systemic perspective can be utilized when dealing with ethics. In the subsequent section we elaborate on this.

\section{WHY LOOK AT BUSINESS ETHICS FROM A SYSTEMIC PERSPECTIVE?}

In 1930, general systems theory was considered a logical-mathematical field (von Bertalanffy, 1972). More than 40 years later, the scope of the field has widened:

... This writer does not see that the humanistic aspects can be evaded unless general systems theory is limited to a restricted and fractional vision. (von Bertalanffy, 1972, p. 424)

There are several features to the topic of business ethics that make a systemic perspective suitable, even desirable. While lack of space does not permit an indepth discussion of this assertion, we take a look at some of the features of business ethics and systems thinking that make a good case for linking them to each other.

First, the humanistic concerns of systems thinking are also an evident dimension of business ethics (Dolenga, 1990). In terms of the humanistic aspect, one can also find clear connections between business ethics and systems thinking (Velasquez and Rostankowski, 1985; cited by Jones, 1991, p. 367).

Second, a recurring theme in previous research on business ethics is that 
of relations. One could possibly even argue that ethics is about relations. Relations between the enterprise and its stakeholders, relations between individuals within a single organization, and relations between the business community and society in general. The concept of relations is also a distinct feature of general systems thinking. In fact, systems are made of relations.

Third, systems are organized into hierarchies (von Bertalanffy, 1968). The concept of hierarchies has been taken into consideration by several researchers in business ethics and related fields. Proposing a conceptual framework for research on corporate social performance, Wood (1991) emphasizes the need to take into consideration the principles of corporate social performance on an institutional, organizational, and individual level. Researchers have studied the ethical values of individuals at different levels in the organizational hierarchy of a single firm (Harris, 1990) and suggested a distinction between the individual and the group level when assessing the ethical performance of organizational members (Gatewood and Carroll, 1991).

There are researchers who even find ethics to be a system discipline per se. According to Pruzan and Thyssen (1990), the systemic orientation of ethics is based on the idea of ethics arising from dialogue. Further, they contend that ethical issues can only be settled by taking a holistic, and therefore systemic, view. Taken together, we argue that the above assertions provide some evidence that business ethics could fruitfully be discussed from a systemic perspective. However, systems thinking is not only one line of thought. Systems design and development is therefore used to exemplify its application. Depending on which approach is taken within the spectrum of systems development methodologies, ethics is treated in different ways. Therefore, in the following section we will look at different methodologies of systems development and their relations to ethics.

\section{EXAMINING "SCHOOLS" OF SYSTEMS DESIGN FROM AN ETHICAL STANDPOINT}

In this section we review and discuss four methodologies for systems design in terms of their explicit and implicit views on ethics. We focus especially on similarities and differences. The methodologies are multimodal methodology, hypersystems, soft systems methodology, and developmental work research. This will enable us to conclude the paper by speculating on the applicability of the various methodologies in business settings.

\subsection{Multimodal Methodology}

de Raadt's (1995) multimodal methodology (MMM) is based on the notion of modalities. These are designed to represent an ordered structure encompassing 
all aspects of human life. The modalities vary from numerical to credal with increasing complexity, each with a fixed content. MMM aims at changing not only information system design, but also social systems on a more general level. According to de Raadt, today's societies are degenerating in terms of ethics and this degeneration is due mainly to an oversimplification of the act of systems design where technological aspects dominate over humanitarian considerations. By discarding the utilitarian and mechanistic management philosophies, a more holistic methodology can be put forward. Systems should be designed taking into account also "ought-aspects," i.e., what the role of the system ought to be and how it should work. These normative considerations imply that ethics are much more important in MMM than in the present practice of systems design. In order to analyze ethical aspects of systems (in our case business organizations), the multimodal approach has appealing characteristics.

There are also other ethical connotations to the works of de Raadt. The author uses the concept of "sphere of sovereignty" "when looking into the role and responsibilities of different systems in society. By means of the sphere of sovereignty, the domination of one system over another, or indeed the destruction of a system by another, is avoided. This could be interpreted as taking an ethical stance toward the act of systems design. Refer to Velasquez and Rostankowski's definition of ethics in Section 3. Systems residing in different modalities should not be permitted to place demands on the members of society that lead to the member neglecting one system (or modality) for the sake of another ("checking for conflict"). This can be related to the idea of including all stakeholders when resolving ethical dilemmas, which is a fundamental building block in several of the works on business ethics (e.g., Pastin, 1994; Hyman et al., 1990). Ethics is not discussed from a relativist perspective. The call for "'order"' as well as the fixed content of each modality implies that what is ethical does not depend on the situation.

\subsection{Hypersystems}

Ivanov's (1991) idea of hypersystems refers to a computer-based implementation of a self-learning social system. In other words, a computer supported application attempting to learn. Core concepts are the interrelated categories of designer, decision maker, client and system philosopher. These categories hold certain opinions ("is/ought judgments") that should be taken in consideration in systems design. The application of hypersystems would enable tapping the opinions of different actors, stimulating communication and involvement. However, Ivanov suggests that consensus might overshadow the truth.

We should therefore prevent that truth. . .be banished and replaced by a value that is reduced to consensual usefulness at the interface between pragmatism and negotiated democratic utilitarianism. (Ivanov, 1991, p. 16) 
Hypersystems would encompass an ethical dimension in the sense that issues such as power would not be overlooked in the design. Moreover, the inclusion of the concept of truth would reduce unethical behavior on the part of pragmatic systems analysts (consultants). It seems that hypersystems is primarily conceptual, i.e., more of an idea than an elaborated methodology.

\subsection{Soft Systems Methodology}

Soft systems methodology (SSM) was developed to be used in broad problem-solving situations where goals cannot be quantified. The overriding idea is that problem situations regarding human affairs cannot be "solved" once and for all, which calls for a process-oriented instead of a technique-oriented approach (Checkland, 1988).

The methodology calls for the analyzer to adapt to the different stakeholderviews, thereby requiring empathy from the analyzer. This emphasis on understanding has ethical overtones (see, e.g., Pastin, 1994).

Another aspect of ethics in SSM is the regard of history as relevant and important in any problem situation. This way, a deeper understanding of the views of different stakeholders may be obtained. Such a participative approach means that all different actors should take part in mapping the system.

Changes should not only be systemically desirable, but also culturally feasible. In SSM, changes are culturally feasible if

... they are adapted to the characteristics of the situation, the people in it, their shared experiences and their prejudices. (Checkland, 1981, p. 181)

By this statement an ethical stance is taken that coincides very well with the business ethics definition in Section 3. It is, however, not clear whether Checkland also would include silent stakeholders such as the environment, customers, and competitors.

A transformation or change should meet three criteria. It should be efficacious, efficient, and effective. These three criteria are sometimes expanded to five, including ethicality and elegance, where the former has demands on the moral correctness of the system (Checkland et al., 1990). In these writings, the meaning of "moral correctness" is not discussed.

\subsection{Developmental Work Research}

As argued by Engeström (1991) and Morris and Holt (1993), a desirable property of developmental work research (DWR) is that it lends itself to analyses beyond one-sided cognitive or structural approaches. A recurring theme in business ethics research is whether the individual or the organization behaves ethi- 
cally. In other words, Engeström's human activity system may be regarded as a link between the individual and the organization.

Ethics does not emerge explicitly in the work of Engeström. But as we see it, his view is also similar to the definition of business ethics offered in Section 3. According to activity theory, a "good" (ethical) system is one about which there is consensus. Engeström tends, however, to place particular emphasis on internal stakeholders.

A distinct feature of DWR is that it analyzes everyday dilemmas against the background of the historically evolving contradictions of the activity system (Saarelma and Engeström, 1993). This historical analysis is the basis of development. DWR advocates a participative approach where experts (e.g., systems analysts) don't lead, but work together with the rest of the workforce. DWR is a form of action research, and as such it is change oriented.

An activity system is much more competent and robust than any of its individual expert members (Engeström, 1991). Activity systems have many voices and many layers. This multitude of voices and layers is both a resource and a source of conflict. By inner contradictions the (ethical) system develops.

\subsection{Comparative Analysis}

In this section, the different methodologies are compared with each other in terms of their overriding purpose, the tools used, and their emphasis on ethics. The extent to which each methodology takes the particular characteristics of the situation into account is also examined. All methodologies are examples of selflearning systems. The emphasis is not on performing an isolated task with a clear-cut beginning and end. Rather, the entire and continuous process is focused. This provides a better climate for ethical behavior (Pastin, 1994). In this respect, some ethical, considerations apply to all the "schools" examined.

When learning systems are discussed, it is natural to bring up the concept of change. Indeed, change is the very essence of a learning system. The different methodologies have different ambitions regarding what should be changed and how it should be done. While de Raadt wants to change the whole society, SSM and DWR work at a lower level. It appears as if Ivanov takes a middle-of-theroad position.

The quest for truth is a driving force in the works of both Ivanov and de Raadt. Certain fundamentals constitute the cornerstones in their respective methodologies. Ethics is one of these comerstones. MMM and, to a lesser extent, Hypersystems are found on the idealistic side, as opposed to SSM and DWR, which both occupy the pragmatic side of the spectrum. One reason could be found in the fact that SSM and DWR both have been developed in real-world problematic situations, whereas MMM and Hypersystems still are on a conceptual level. 
All methodologies appear to agree that consensus is an important aspect when resolving ethical issues. However, even with regard to the emphasis on consensus, the four schools have clear differences.

Historical analyses are explicit only in the works of Engeström and Checkland. However, the systemic nature of MMM and Hypersystems would imply that a system cannot be understood in a snap-shot fashion without regarding the past and the future. Historical and future-oriented analyses are necessary in order for ethics to be taken into proper consideration (e.g., Kahn, 1990). It appears as if SSM and DWR both adopt a more situational view of ethics and consensus. Every situation must be handled separately, but still in compliance with the systemic view. For example, seemingly identical situations may differ in that their histories are disparate.

From our supplied definitions of (business) ethics, and after having justified a systemic approach to the study of ethics, we have examined four systems development methodologies from an ethical point of view. This review can be summarized and illustrated as in Table $\mathbf{I}$.

\section{CONCLUDING REMARKS}

In the initial part of the present paper, we suggested that the old perception of ethics in business gradually has changed. Still, there are some indications that the values of individual managers are practically the same today as 10 years ago (Premeaux and Mondy, 1993). One can therefore hypothesize that any change would be more on the superficial level of society than among individual managers. Researchers stress the risk of ethics becoming a "management fad," which may occur if ethics concern only the professional situation (work ethics). For ethics to develop beyond this, it must relate to the individual value systems of managers. Since individual values often are deeply rooted, this may mean that a real change in ethical behavior will not occur until a new generation has reached managerial positions.

When it comes to the applicability of the methodologies in ethical problem situations, there are clearly some differences. Engeström's DWR and Checkland's SSM both have been developed to work in real-world situations in today's society. Their applicability has also been proven. Therefore, they could probably be efficient in everyday ethical problem situations. However, when it comes to explicit ethical concerns, they are seldom emphasized in these methodologies.

Hypersystems is still at a developmental stage, and it is therefore difficult to foresee how it will affect business ethics. It has, however, some similarities to the multimodal methodology of de Raadt. MMM is more elaborated but we feel that the holistic nature of the methodology impairs it from dealing with smaller problems or issues that may be important to some members of society. On the other hand, its purpose is rather a call for a new order altogether. 


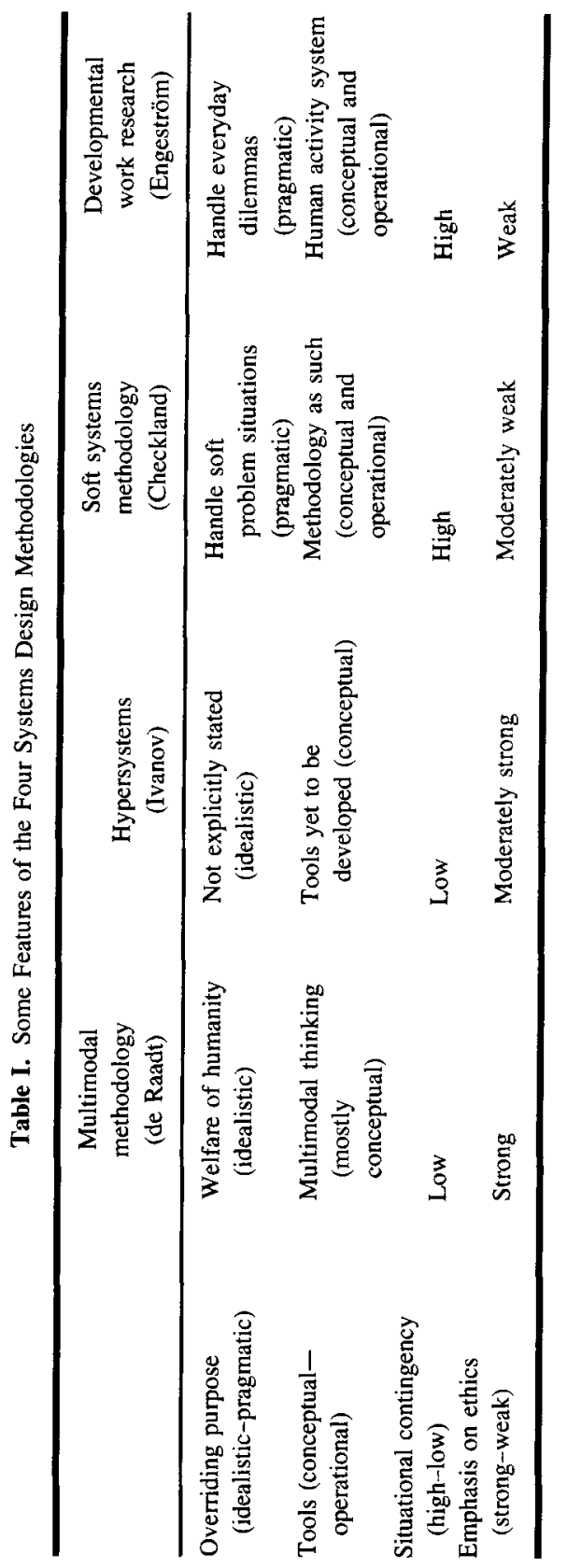


Its impact on business ethics in the short run will therefore probably be modest. Still, as pointed out by James (1956; cited by Ivanov, 1991), ethics becomes especially important in other than everyday situations. This supports the general idea of developing a systems methodology for a broader purpose, which would by definition, include ethics.

As a result of this review, two important aspects emerge concerning business ethics in the realm of systems theory: first, the issue of practical applicability and, second, the issue of whether ethics can be included in the analysis in a meaningful way. The more "practically oriented" methodologies (DWR and SSM) seem to lack a clear ethical stance, while the more ethically concerned Hypersystems and MMM can be considered to have limited practical applicability. We feel that systems theory can contribute to the field of business ethics, provided that practical applicability and a clear ethical stance can be combined. The ideal methodology, both applicable and with a clear emphasis on ethics, is yet to be developed.

\section{REFERENCES}

Bird, F. B., and Waters, J. A. (1989). The moral muteness of managers. Calif. Manage. Rev. Fall, 74-88.

Brehmer, B. (1992). Dynamic decision making: Human control of complex systems. Acta Psychol. 81, 211-241.

Carmichael, S., and Drummond, J. (1989). Good Business-A Guide to Corporate Responsibility and Business Ethics, Century Business Books, London.

Carr, A. Z. (1994). Is business bluffing ethical? In Drummond, J., and Bain, B. (eds.), Managing Business Ethics, Butterworth Heinemann, Oxford.

Carroll, A. B. (1978). Linking business ethics to behaviour in organizations. SAM Adv. Manage. J. 43, 4-11.

Checkland, P. (1981). Systems Thinking, Systems Practice, John Wiley \& Sons, Chichester.

Checkland, P. (1988). Soft systems methodology: An overview. J. Appl. Syst. Anal. 15, 27-30.

Checkland, P., Forbes, P., and Martin, S. (1990). Techniques in soft systems practice. Part 3: Monitoring and control in conceptual models and in evaluation studies. J. Appl. Syst. Anal. 17, 29-37.

de Raadt, J. D. R. (1995). Expanding the horizon of information systems design: Information technology and cultural ecology. Syst. Res. 12, 185-199.

Dillon, G. C. (1991). Does it pay to do the right thing? Across the Board July-August, 15-17.

Dolenga, H. E. (1990). An iconoclastic look at business ethics. Adv. Manage. J. 55(4), 13-17.

Engeström, Y. (1991). Developmental work research: Reconstructing expertise through expansive learning. In Nurminen, M. I., and Weir, G. R. S. (eds.), Human Jobs and Computer Interfaces, Elsevier Science, North-Holland, Amsterdam.

Gatewood, R. D., and Caroll, A. B. (1991). Assessment of ethical performance of organization members: A conceptual framework. Acad. Manage. Rev. 16(4), 667-690.

Gundling, E. (1991). Ethics and working with the Japanese. The entrepreneur and the "elite course," Calif. Manage. Rev. 33(3), 25-39. 
Hambrick, D. C., and Mason, P. A. (1984). Upper echelons: The organization as a reflection of its' top management. Acad. Manage. Rev. 9, 193-206.

Hanson, D. P. (1991). Managing for ethics, some implications of research in the prisoner's dilemma game. Adv. Manage. J. 56(1), 16-20.

Harris, J. R. (1990). Ethical values of individuals at different levels in the organizational hierarchy of a single firm. J. Bus. Ethics 9(9), 741-750.

Hoffman, W. M. (1994). What is necessary for corporate moral excellence? In Drummond, J., and Bain, B. (eds.), Managing Business Ethics, Butterworth Heinemann, Oxford.

Hyman, M. R., Skipper, R., and Tansey, R. (1990). Ethical codes are not enough. Bus. Horizons March-April, 15-22.

Ivanov, K. (1991). Hypersystems. A Base for Specification of Computer-Supporter Self-Leaming Social Systems. Research report in information processing and computer science No. 13, Institute of Information Processing, Administrative Data Processing, Umeå University, Umeå.

Jones, T. M. (1991). Ethical decision making by individuals in organizations: An issue-contingent model. Acad. Manage. Rev. 16(2), 366-395.

Kahn, W. A. (1990). Toward an agenda for business ethics research. Acad. Manage. Rev. 15(2), 311-328.

Khalil, O. E. M. (1993). Artificial decision-making and artificial ethics: A management concern. J. Bus. Ethics 12, 313-321.

Kitching, J., Lightfoot, G., and Jarvis, R. (1994). The pricing decision in small firms: Subjectivity and judgement. Kingston University, Paper presented at the 17th conference of the European Accounting Association, Venice, Italy.

Klein, H. K., and Hirschheim, R. (1991). Rationality concepts in information system development methodologies. Account. Manage. Inform. Technol. 1(2), 157-187.

Maclagan, P. (1992). Management development and business ethics: A view from the U.K. J. Bus. Ethics 11, 321-328.

Maclagan, P., and Snell, R. (1992). Some implications for management development of research into managers' moral dilemmas. Br. J. Manage. 3, 157-168.

Miller, D. R., and Toulouse, J. M. (1986). Chief executive personality and corporate strategy and structure in small firms. Manage. Sci. 32(11), 1389-1409.

Morris, G. R., and Holt, A. W. (1993). Activity theory and the analysis of organizations. Hum. Organiz. 52(1), 97-109.

Nash, L. L. (1994). Why business ethics now? In Drummond, J., and Bain, B. (eds.), Managing Business Ethics, Butterworth Heinemann, Oxford.

Pastin, M. (1994). Ethics as an integrating force in management. In Drummond, J., and Bain, B. (eds.), Managing Business Ethics, Butterworth Heinemann, Oxford.

Premeaux, S. R., and Mondy, R. W. (1993). Linking management behaviour to ethical philosophy. J. Bus. Ethics 12, 349-357.

Pruzan, P., and Thyssen, O. (1990). Conflict and consensus: Ethics as a shared value horizon for strategic planning. Hum. Syst. Manage. 9, 135-151.

Saarelma, O., and Engeström, Y. (1993). New Work-New Tools: Information System Development in the Context of Developmental Work Research, The Working Health Center Project, Helsinki, Finland, and the Laboratory of Comparative Human Cognition, University of California, San Diego.

Singer, A. E. (1994). Strategy as moral philosophy. Strat. Manage. J. 15, 191-213.

Stead, W. E., Worrell, D. L., and Stead, J. G. (1994). An integrative model for understanding and managing ethical behaviour in business organizations. In Drummond, J., and Bain, B. (eds.), Managing Business Ethics, Butterworth Heinemann, Oxford. 
von Bertalanffy, L. (1968). General System Theory, George Braziller, New York.

von Bertalanffy, L. (1972). The history of general systems theory. In Klir, G. J. (ed.), Trends in General Systems Theory, Wiley-Interscience, New York.

Weber, M. (1947). The Theory of Economic and Social Organization, Free Press, New York.

Wood, D. J. (1991). Corporate social performance revisited. Acad. Manage. Rev. 16(4), 691-718. 